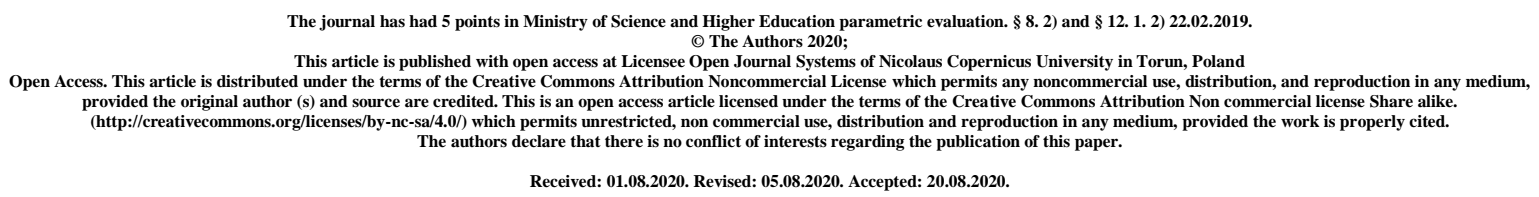

\title{
Comparison of the mechanisms of action of antidepressants and their side effects
}

\author{
Magdalena Wasielewska
}

Magdalena Wasielewska; ORCID: 0000-0001-8638-3732; E-mail: w.magdalena1 @ gazeta.pl Nicolaus Copernicus University in Toruń Collegium Medicum in Bydgoszcz, ul. Jagiellońska 13-15, 85-067 Bydgoszcz, Major Pharmacy

\begin{abstract}
Introduction: There are 4 groups of LPs divided according to the mechanism of action. They act on the brain by modulating monoaminergic systems, causing a series of side effects such as insomnia, sedation, anxiety, and a problem of a sexual nature. By appropriately selecting the drug and its dose, the negative effects of the therapy can be avoided.

Aim : Comparison of the mode of action of a drug from a given group of antidepressants and description of its side effects.

State of knowledge : An example from the first group of drugs with a receptor mechanism of action is trazodone - it acts on many receptors. The combined effect of the drug on all three receptors will significantly improve sleep in all its phases. It is as effective a drug as TLPD, and due to the lack of anticholinergic and cardiotoxic effects, it has a better tolerance and safety profile. It works quickly and improves sleep parameters, which is responsible for faster improvement of the patient's mental state. An example of a drug from the second group of drugs with a different mechanism of action is agomelatine. It is a synthetic analog of melatonin.
\end{abstract}


The simultaneous agonist action on one receptors and antagonist action on the other causes a number of changes in the CNS, which are responsible for the antidepressant effect. The effects of the treatment can be seen after 2 weeks of use. The drug of the third group neurotransmitter reuptake inhibitors there is bupropion. It intensifies the dopaminergic transmission. It does not disturb the sexual sphere, but increases insomnia as a side effect.

Summary : By selecting the appropriate LP and its dose, side effects can be avoided.

Key words: depression; mental disorders; antidepressants; side effects

\section{Introduction}

Recently, the classic concept of antidepressant drugs has undergone many modifications, mainly due to the emergence of drugs with atypical mechanisms of action, and also due to the advancement of knowledge about the mechanisms of stress and depression.

On the one hand, traditional drugs, as well as newer ones with atypical mechanisms of action, are still insufficiently effective in many patients and are burdened with many side effects, such as: insomnia, dementia, sedation, sexual problems, anxiety. [1]

The monoaminergic systems and their neurotransmitters: noradrenaline, serotonin, dopamine played a great role in the development of pharmacotherapy of central nervous system diseases. Over the past 60 years, different categories of antidepressant drugs (LPs) have emerged, the first of which were discovered by chance. They all act on the brain by modulating monoaminergic systems. The observation that these drugs relieve the symptoms of the disease in most depressed patients gave rise to the monoaminergic hypothesis of depression, which assumed that the disease was caused by deficits in neurotransmitters in synapses. Hence, most of the known and currently used LPs act on the basis of increasing the level of neurotransmitters, either by inhibiting douronal reuptake, or by inhibiting enzymes catabolizing these transmitters.

\section{Classification of antidepressants}

Due to the mechanism of action and chemical structure, the following are distinguished:

- Neurotransmitter reuptake inhibitors - these drugs inhibit the reuptake of neurotransmitters (incl. serotonin. noradrenaline. dopamine or to a lesser extent others monoamines) with synaptic cleftby increasing the concentration of these monoamines in it.

Tricyclic antidepressants (TCAs) - nonselective norepinephrine and serotonin reuptake inhibitors - e.g. clomipramine. amitriptyline. imipramine. desipramine. dibenzepin. doxepin. opipramol. pipofezine. noxiptiline

$>\quad$ A four-ring (tetracyclic) antidepressant drug - noradrenaline reuptake inhibitor - e.g. maprotiline

$>\quad$ Serotonin and norepinephrine reuptake inhibitors (SNRI) - e.g. venlafaxine. milnacipran. duloxetine

$>\quad$ Norepinephrine reuptake inhibitors (NRI) - e.g. reboxetine

$>\quad$ Selective serotonin reuptake inhibitors (SSRI) - e.g. fluoxetine. fluvoxamine. paroxetine. sertraline. citalopram. escitalopram. dapoxetine, Zimelidin

$>\quad$ Norepinephrine and dopamine reuptake inhibitors (Ndri) - e.g. bupropion and amineptine 
- Drugs with receptor mechanisms of action

$>\quad$ antagonists alpha2 receptor - e.g. mianserin

$>\quad$ inhibitors serotonin uptake, blocking serotonin receptor 5HT2 (SARI) - e.g. trazodone and nefazodone

$>\quad$ antagonists adrenergic receptors alpha2, 5HT2, 5HT3 - e.g. mirtazapine

- Monoamine oxidase inhibitors (MAO)

$>\quad$ Reversible monoamine oxidase inhibitor type A (MAO-A) - e.g. moclobemide

$>\quad$ Irreversible monoamine oxidase inhibitor - e.g. phenelzine. isocarboxazid. tranylcypromine. iproniazid

- Drugs with other mechanisms of action

$>\quad$ Increasing serotonin reuptake - e.g. tianeptine

$>\quad$ agonist melatonergic MT1 and MT2 receptors, and a 5-HT2C receptor antagonist e.g. agomelatine

$>\quad$ Precursor acetylcholine - e.g. deanol

$>\quad$ Serotonin reuptake inhibitor and partial agonist of the 5-HT1 receptor - e.g. vilazodon

$>\quad$ Serotonin reuptake inhibitor and serotonin modulator and stimulator - e.g. vortioxetine [2]

\section{Aim}

The aim of this study is to compare the mode of action of a drug from a given group of antidepressants, which differ in the mechanism of action and the physiological consequences they cause, i.e. more precisely - the treatment of depression and the side effects they cause. Examples of antidepressants from each group will be presented, in addition to MAOIs, along with their specifications and description of action.

\section{Description of the state of knowledge}

\section{Trazodone}

Trazodone is an antidepressant drug of the group of serotonin antagonists and reuptake inhibitors (SARIs). This drug was introduced into circulation in the 1970s. Ten years later it became the most prescribed drug for depression in the United States. [3] It is defined as an atypical antidepressant drug due to its lack of activity in classical pharmacological tests. It has been proven that long-term administration of trazodone leads to a decrease in the number of $\beta$-adrenergic and serotonin receptors. [4]

\section{Mode of action}

Trazodone acts directly on the serotonergic system as an antagonist of 5-HT2A and HT2C receptors and an inhibitor of the serotonin transporter (SERT). In addition, it blocks the following receptors: histamine $\mathrm{H} 1$ and adrenergic $-\alpha 1$ and $\alpha 2$. The affinity for trazodone differs for individual receptors, which has a significant influence on the selection of the drug dose. The 5-HT2A receptor has the highest affinity, the lower $\alpha 1$, followed by H1, $\alpha 2$, SERT and finally the receptor with the lowest affinity HT2C. This sequence explains the clinical properties of trazodone as a multifunctional drug. [5] The clinical effects of trazodone are due to its antagonist activity at the first three receptors mentioned above, when doses of 25 to 150 $\mathrm{mg}$ are used. The combined effect of the drug on all three receptors will significantly improve sleep in all its phases. 
- $\quad$ Blocking the 5-HT2A receptor significantly improves the quality of sleep - it shortens its latency, improves its continuity, increases the amount of deep sleep without affecting REM sleep. $[6,7]$ It also reduces the severity of anxiety and improves sleep.

- $\quad$ Blocking the 5-HT2C receptor improves appetite and reduces the severity of sexual dysfunction.

- $\quad$ Blocking the $\mathrm{H} 1$ and $\alpha 2$ receptors causes excessive sleepiness (sedative effect) [8], and additional blocking of the $\alpha 1$ receptor - orthostatic decrease in blood pressure. [9]

- Blocking the $\alpha 1$ receptor is associated with the improvement of sexual functions, which are disturbed in depressive syndromes, and most antidepressants additionally intensify them.

- $\quad$ Blocking the 5-HT2 receptor reduces the risk of side effects that are common with the use of drugs that inhibit serotonin reuptake (SSRI, SNRI). These symptoms include, but are not limited to: anxiety, insomnia, sexual dysfunction, decreased appetite. [10]

\section{Controlling the release of trazodone in the body}

Trazodone CR is a controlled release form of the drug. As a result, the plasma concentration of the drug increases slowly compared to the conventional version of the drug. The important thing is that the concentration of the drug is maintained longer at the therapeutic level, which allows its use only once a day and clearly improves its tolerance. [11] The drug is almost completely absorbed from the gastrointestinal tract. It is highly bound to plasma proteins, about $90 \%$, mainly to albumin. [12] Trazodone is largely excreted as metabolites: $75 \%$ in the urine and $25 \%$ in the bile. It is metabolized in the liver by the cytochrome P450 isoenzyme 3A4.

\section{Clinical use of trazodone}

Clinical trials of trazodone show a wide spectrum of activity, not only in the treatment of depression with anxiety disorders.

This drug has been shown to be effective at a dose of 150-600 mg / day. Trazodone was compared with the tricyclic drugs in the past such drugs (TLPD), eg: imipramine [13], amitriptyline [14] and doxepin [15]. Studies have shown that trazodone is as effective an antidepressant as TLPD, and at the same time, due to the lack of anticholinergic and cardiotoxic effects, it has a better tolerance and safety profile. It works quickly, producing an anxiolytic effect and improving sleep parameters. This may be responsible for faster improvement of the patient's mental state. [16]

Currently, the most commonly used antidepressants are SSRIs. Therefore, the effect of trazodone was compared with one of the representatives of this group of drugs - fluoxetine. [17] The results of these studies indicate that there are no significant differences in the effectiveness of SSRIs and trazodone in the treatment of depressive disorders. Additionally, trazodone showed an improvement in all sleep parameters and a reduction in anxiety and anxiety shortly after starting treatment.

An additional advantage of trazodone, as shown by many studies, is that it is not often withdrawn by patients and is well tolerated, which maintains the effectiveness of the treatment and can prevent relapses rotom of depressive episodes. [18] 


\section{Agomelatine}

It is an antidepressant drug that is an agonist of MT1 and MT2 melatonergic receptors and an antagonist of 5-HT2C receptors. It is a synthetic analog of melatonin. It was synthesized as a result of the search for a substance that easily crosses the blood-brain barrier and synchronizes the circadian rhythm. [19] In addition to regulating sleep, it acts as an antidepressant and anxiolytic. [20]

\section{Mode of action}

Agomelatine turned out to be a strong agonist of melatoninergic receptors: $\mathrm{MT}_{1}$ and MT2, and a slightly less potent 5-HT2C serotonergic receptor antagonist. The simultaneous agonist effect on one receptors and antagonist effect on the other causes a number of changes in the central nervous system, which are responsible for the antidepressant effect: [21]

- Increase in dopaminergic and noradrenergic transmission in the prefrontal cortex. [22]

- Increased activation of the serotonergic 5-HT1A receptor without changes in its sensitivity [23]

- $\quad$ Normalization of disturbed circadian rhythms and sleep disorders [24]

- $\quad$ Neuroprotective effect [25]

- Decreased glutamatergic activity as a result of 5-HT2C receptor antagonism

\section{Controlling the release of agomelatine in the body}

Agomelatine is rapidly absorbed from the gastrointestinal tract. The maximum concentration in the blood is reached about 1-1.5 hours after taking a single dose. [26] Despite very good absorption, its bioavailability is slightly over 3\%, which results from the so-called "First pass effect". An interesting fact is that the bioavailability of agomelatine in women is 2 times higher than in men. [27] The elimination of agomelatine from the body is metabolic, only a very small amount is excreted in the urine. It is metabolized mainly by the isoenzyme CYP1A2.

\section{Clinical use of agomelatine}

A significant disadvantage of antidepressant treatment is the delay between the start of treatment and the first positive effects of the drug. It often takes several weeks, which makes the patient reluctant to continue the treatment. Agomelatine works quickly, as a significant difference is visible after two weeks of use at a dose of $25 \mathrm{mg}$. [28] Agomelatine was also more effective than fluoxetine based on the CGI-S scale. This drug is also beneficial for sleep disorders. It is much better than the effectiveness of other drugs, such as sertraline, fluoxetine, escitalopram. [26]

\section{Bupropion}

It is an antidepressant drug belonging to the group of norepinephrine and dopamine reuptake inhibitors - NDRI for short. It has been used for many years in the treatment of depression, since 1989 in the United States, it is recommended for the treatment of the so-called MDD major depressive disorder. Compared to other drugs used in the treatment of depression, it is a drug with quite specific action. It has no significant effect on the postsynaptic receptors for histamine, serotonin, acetylcholine, $\alpha$ - and $\beta$-adrenergic and postsynaptic dopamine receptors, resulting in fewer side effects. 


\section{Mode of action}

Most drugs used to treat depression act through reuptake and on the serotonin 5HT and noradrenaline (NA) receptors. However, the mechanisms involved in these two neurotransmitters are not the only ones involved in the pathophysiology of depression. Dopamine (DA) is considered to be a "hedonistic" neurotransmitter, associated with the feeling of pleasure, motivation, involvement in activities directed outside the body, including the satisfaction of libido needs. [29]

In research on dopaminergic receptors in people with depression revealed:

- Decrease of the concentration of dopamine metabolites in the cerebrospinal fluid

- The low level of these metabolites did not show a clear correlation with the response to TLPD therapy

- $\quad$ The neuroimaging studies conducted so far on binding the potential of dopaminergic receptors in depression have shown that depression is associated with the state of reduction of DA transmission.

The mechanisms of lowering DA transmission in depression may be different:

Decreased signal transduction due to changes in receptor number or function or altered intracellular mechanisms.

$>\quad$ Reduction of DA release from presynaptic neurons

It can therefore be concluded that the action of bupropion enhances dopaminergic transmission due to the fact that DA stays longer in the synaptic cleft stimulating postsynaptic receptors. [30]

\section{Controlling the release of bupropion in the body}

In animal studies, bupropion and its metabolites have been shown to reduce dopamine reuptake as well as a whole host of other mechanisms by which they affect DA transmission. [31] In the cited study, 3 hours after drug administration, the average DA transporter occupancy by bupropion and its metabolites was $26 \%$. This level was maintained after 24 hours when it was $25 \%$.

\section{Clinical use of bupropion}

In depression, problems of the sexual sphere are a common phenomenon. The most common sexual disorders include: decreased libido, erectile dysfunction, and orgasmic disorders. [32] The lack of effect of bupropion on serotonergic receptors is thought to be the reason why side effects such as sexual dysfunction are 4-6 times less frequent with bupropion than with SSRIs and venlafaxine. However, studies by Jefferson et al. Have shown that in as many as $11 \%$ of cases, bupropion causes insomnia as a side effect. It is worth emphasizing, however, that excessive sedation is not observed in long-term treatment. The main advantage of using this product is that it does not cause sexual dysfunction, which may contribute to the success of antidepressant therapy. [33]

\section{Summary}

After analyzing three examples of drugs from different groups of antidepressants, it can be concluded that the way they act on specific receptors determines the speed of their action, the dose needed to achieve a therapeutic effect and what side effects may occur. 
Therefore, skillful selection of a dose and a drug from a given category is of great importance and determines whether the drugs will not be discontinued by the patient, which would lead to the lack of treatment effects, and whether the drugs will allow the patient to function normally during the therapy itself.

\section{References}

[1] Kostowski W. Współczesne kierunki badań nad patomechanizmem stresu i depresji i ich znaczenie w kształtowaniu poglądów na działanie leków przeciwdepresyjnych. Psychiatria, 2004; 2 (1): 63-71.

[2] https://www.depresjaza.pl/leki (13.08.2020)

[3] Burke MJ, Preskorn SEE. Short-term treatment of mood disorders with standard antidepressants. W: Bloom FE, Kupfer DJ, red, Psychopharmacology: The fourth generation of Progress. New York: Raven Press; 1995, s. 1053-1065.

[4] Riblet LA, Taylor DP. Pharmacology and neurochemistry of trazodon. J. Clin. Psychopharmacol. 1981; 1 (supl): 17-22.

[5] Stahl SM. Mechanism of action of trazodon: a multifunctional drug. CNS Spectr. 2009; 14: 536-546.

[6] Oberndorfer S, Saletu-Zychlarz G, Saletu B. Effects of selective serotonin reuptake inhibitors on objective and subjective sleep quality. Neuropsychobiol. 2000; 42: 69-81.

[7] Le Bon O. Contribution of sleep research to the development of New antidepressant. Dialog. Clin. Neurosc. 2005; 7: 305-313.

[8] Shigemoto Y, Fujii Y, Shinomiya K, Kamei C. Participation of histaminergic H1 and noradrenergic alpha 1 receptors in orexin A-induced wakefulness in rats. Brain Res. 2004; 1023: 121-125.

[9] Landowski J. Wybór leku przeciwdepresyjnego. Dysk. Depr. 2001; 10: 2-11.

[10] Stahl SM. Mechanism of action of trazodon: a multifunctional drug. CNS Spectr. 2009; 14: 536-546.

[11] Monteleone P, Delrio G. Pharmacocinetic and pharmacodynamic characteristics of a controlled release formulation of trazodone versus the conventional formulation in healthy volunteers. Ital. J. Neurol. Sc. 1993; 14: 443-449.

[12] Haria M, Fitton AS, McTavish D. Trazodone. A review of its pharmacology, therapeutics use in depression and therapeutic potential in other disorders. Drugs Aging 1994; 4: 331-335.

[13] Mann J, Georgotas A, Newton R, Gerschon S. A controlled study of trazodone, imipramine and placebo in outpatients with endogenous depression. J. Clin. Psychopharmacol. 1981; 42 (1): 75-80.

[14] Carney PA, Healy D, Leonard BE. A double-blind study to compare trazodone with amitryptyline in depressed patients. The role of trazodone in antidepressant therapy: safety and clinical efficacy. Psychopathol. 1984; 17 (supl. 2): 37-38.

[15] Poldinger W. Experiences with doxepine and trazodone in the therapy with outpatients suffering from depression. Psychopathol. 1984; 17: 30-36.

[16] Cubała W, Landowski J. Spektrum zastosowań klinicznych trazodonu. Psychiatr. 2011; 8: $1-6$.

[17] Beasley CM Jr, Dornseif BE, Pultz JA, Bosomworth JC, Sayler ME. Fluoxetin versus trazodone : Efficacy and activating-sedating effects. J. Clin. Psychiatry 1991; 52: 294-299. 
[18] Fabre LF Jr. United States experience and perspective with trazodone. Clin. Neuropharmacol. 1989; 12 (supl. 1): 11-17.

[19] Le Strat Y, Gorwood P. Agomelatine, an innovative pharmacological response to unmet needs. J. Psychopharmacol. 2008; 22: 4-8.

[20] Papp M, Litwa, Gruca P, Mocaer E. Anxiolytic-like activity of agomelatine and melatonin in three animal models of anxiety. Behav. Pharmacol. 2006; 17: 9-18.

[21] Stahl SM. Novel mechanizm of antidepressant action: norepinephrine and dopamine disinhibition (NDDI) plus melatonergic agonism. Int. J. Neuropsychopharmacol. 2007; 10 (5): 575-578.

[22] Millan MJ, Gobert A, Lejeune F i wsp. The novel melatonin agonist agomelatine (S20098) is an antagonist at 5-hydroxytryptamine2C receptors, blockade of which enhances the activiy of trontocortical dopaminergic and adrenergic pathways. J. Pharmacol. Exp. Ther. 2003; 306: 954-964.

[23] Hanoun N, Mocaer E, Boyer PA, Hamon M, Lanfumey L. Differental effects of the novel antidepressant agomelatine (S20098) versus fluoxetine on 5-HT1A receptors in the rat brain. Neuropharmacology 2004; 47: 515-526.

[24] Zupancic M, Guilleminault C. Agomelatine: a preliminary review of a New antidepressant. CNS Drugs 2006; 20 (12): 981-992.

[25] Gressens P, Schwedimann L, Husson I i wsp. Agomelatine, a melatonin receptor agonist with 5-HT2C receptor antagonist properties, protects the developing murine white matter against excitotoxicity. Eur. J. Pharmacol. 2008, 588: 58-63.

[26] Hale A, Coral RM, Mencacci C, Ruiz JS, Severo CA, Gentil V. Superior antidepressant efficacy results of agomelatine versus fluoxetine in severe MDD patients: a randomized, doubleblind study. Int. Clin. Psychopharmacol. 2010, 25: 305-314.

[27] European Medicine Agency: Evaluation of medicines for human use - CHMP Assessment Report for http://www.emea.europa.eu/humandocs/PDFs/EPAR/valdoxan/H-915-en6.pdf. (6.08.2020)

[28] Stahl SM, Fava M, Trivedi MH, Caputo A, Post A. Agomelatine in the treatment of major depressive disorder: a multicenter, randomized, double-blind, placebo-controlled trial. J. Clin. Psychopharmacol. 2010; 30: 135-144.

[29] Dunlop BW, Nemerhoff CB. The role of dopamine in the pathophysiologiy of depression. Arch. Gen. Psychiatry 2007; 64: 327-337.

[30] Learned-Coughlin SM, Bergstrom M, Savitcheva I, Ascher J, Schmith VD, Langstrom B. In vivo activity of bupropion at the human dopamine transporter as measures by positron emission tomography. Biol. Psychiatry 2003; 53: 800-805.

[31] Panksepp J, Burgdorf J. The neurobiology of positive emotions. Neurosc. Biobehavior Rev. 2006; 30: 173-187.

[32] Angs J. Sexual problems in health and depressed persons. Int. Clin. Psychopharmacol. 1998; (13) 1: 28-35.

[33] Jefferson JW, Pradko JF, Muir KT. Bupropion for major depressive disorder: pharmacokinetic and formulation considerations. Clin. Ther. 2005; 27: 1685-1695. 